\title{
Dynamic strain aging in Haynes 282 superalloy
}

\author{
Magnus Hörnqvist ${ }^{1,2, a}$, Ceena Joseph $^{3}$, Christer Persson $^{3}$, Jonathan Weidow ${ }^{2}$, and Haiping Lai ${ }^{2}$ \\ ${ }^{1}$ GKN Aerospace Engine Systems, R\&T Centre, 46181 Trollhättan, Sweden \\ ${ }^{2}$ Chalmers University of Technology, Department of Applied Physics, 41296 Göteborg, Sweden \\ ${ }^{3}$ Chalmers University of Technology, Department of Materials \& Manufacturing Technology, 41296 Göteborg, Sweden
}

\begin{abstract}
Haynes 282 is a newly introduced Ni-based superallony, developed to provide a combination of hightemperature mechanical properties, thermal stability and processability. The present contribution investigates the effect of dynamic strain aging (DSA) on the deformation behaviour of Haynes 282 during monotonic and cyclic loading. It is shown that DSA (presumably related to carbon diffusion based on rough estimates of the activation energy) completely dominates the development of the stress during cycling at intermediate temperatures, leading to extensive cyclic hardening and serrated yielding. However, no clear effects on the fatigue life or the resulting dislocation structure could be observed. The tensile properties were not severely affected, in spite of the presence of extensive serrated yielding, although a reduction in ductility was observed in the DSA temperature regime. During monotonic loading at lower strain rates indications of an additional DSA mechanism due to substitutional elements were observed.
\end{abstract}

\section{Introduction}

Haynes 282 is a newly introduced Ni-based superalloy, developed to provide a combination of high-temperature mechanical properties, thermal stability and processability $[1,2]$. One of the most important properties of a superalloy intended for use in gas turbine engines, land based or airborne, is the resistance to low cycle fatigue (LCF) loads induced by thermal and mechanical cycles in service. Locally, the material will experience plastic deformation in each cycle, leading to initiation and growth of fatigue cracks. The resistance to crack initiation is controlled by several factors, one being the mode of plastic deformation, i.e. the interaction between dislocations and hardening precipitates. The resulting dislocation structure will control the stress-strain response on a macro-scale, as well as slip localization and crack initiation on a microscale.

In addition to the precipitate-dislocation interactions, which generally dominate the mechanical response, repeated locking and un-locking of dislocations by solute atoms may cause dynamic strain ageing (DSA) to occur under specific combinations of temperatures and strain rates [3]. This is well known to occur in precipitation hardened Ni-base superalloys, and has been correlated to the presence of carbon at intermediate temperatures $\left(<550^{\circ} \mathrm{C}\right)$ [4-9] and solute elements (typically $\mathrm{Cr}$ or $\mathrm{Mo})$ at higher temperatures $\left(>550^{\circ} \mathrm{C}\right)$ [6-9]. Except for the serrated yielding (Portevin-Le Chatelier effect) DSA typically leads to increased stresses and reduced ductility during monotonic loading [10]. During LCF increased

\footnotetext{
${ }^{a}$ Corresponding author: magnus . hornqvist@gknaerospace . com; magnus.hornqvist@chalmers.se
}

cyclic hardening, reduced plastic strain amplitudes and decreased fatigue lives are typically observed [11].

The present contribution investigates the effect of DSA on the monotonic and LCF deformation behaviour of Haynes 282. It is shown that DSA (presumably related to carbon diffusion based on rough estimates of the activation energy) completely dominates the development of the stress during cycling at intermediate temperatures, leading to extensive cyclic hardening and serrated yielding. However, no clear effects on the fatigue life or the resulting dislocation structure could be observed. The tensile properties were not severely affected, in spite of the presence of extensive serrated yielding, although a reduction in ductility was observed in the DSA temperature regime. During monotonic loading at lower strain rates indications of an additional DSA mechanism due to substitutional elements were observed.

\section{Experimental}

The nominal composition of Haynes 282 (in wt. \%) is: $\mathrm{Ni}-20 \mathrm{Cr}-10 \mathrm{Co}-10 \mathrm{Mo}-2.1 \mathrm{Ti}-1.5 \mathrm{Al}-1.5 \mathrm{Fe}-0.3 \mathrm{Mn} 0.15 \mathrm{Si}$ $-0.06 \mathrm{C}-0.005 \mathrm{~B}$ ( $\mathrm{Fe}, \mathrm{Mn}$ and $\mathrm{Si}$ values are maximum allowable levels). The tested material was obtained in the form of mill-annealed bars (100 $\mathrm{mm}$ in diameter, grain size ASTM 3.5-4), which were stabilized and aged. The resulting gamma prime precipitates were roughly spherical in shape and had an average diameter of around $30-40 \mathrm{~nm}$ (as measured by using the $\gamma^{\prime}$ superlattice reflection for dark field imaging in the TEM). There was also a small population of larger gamma prime particles, in the order of $100 \mathrm{~nm}$. Besides the primary MC carbides, the stabilisation treatment resulted in intergranular $\mathrm{M}_{6} \mathrm{C}$ carbides. 
LCF specimens were machined from the bar with the loading axis in the longitudinal direction. The specimens had cylindrical gage sections with $6.35 \mathrm{~mm}$ diameter. Fully reversed push-pull tests (strain ratio $R=-1$ ) were performed in strain control, with the strain measured by an extensometer at the gage length. A total strain amplitude of $1.0 \%$ was employed at a frequency of $0.5 \mathrm{~Hz}$ (strain rate $0.02 \mathrm{~s}^{-1}$ ). For the elevated temperature tests a radiation-heating furnace was used to obtain the desired temperatures $\left(400,550,650\right.$ and $\left.730^{\circ} \mathrm{C}\right)$.

Tensile tests were carried out at temperatures between room temperature and $650^{\circ} \mathrm{C}$ in stroke control. The stroke rate corresponded to a strain rate of $1 \times 10^{-4} \mathrm{~s}^{-1}$ at the start of the test, and was increased to $1 \times 10^{-3} \mathrm{~s}^{-1}$ after $8 \%$ total strain.

Specimens for transmission electron microscopy (TEM) investigations were performed by the liftout technique in an FEI Versa combined FIB/SEM (focused ion beam/scanning electron microscope) dualbeam instrument. The specimens were extracted from the gage section, around $2 \mathrm{~mm}$ below the fracture surface. TEM studies were performed in a FEI Tecnai G2 at $200 \mathrm{kV}$ acceleration voltage.

\section{Results and discussions}

\subsection{LCF tests}

Figure 1a shows the development of the stress amplitude with cycle number for all tested temperatures. The specimen tested at $400^{\circ} \mathrm{C}$ shows a dramatically increased cyclic hardening, compared to both lower and higher temperatures. At this temperature the stresses increase continuously until the onset of crack growth towards the very end of the fatigue life. This has also been previously observed in other superalloys, such as Waspaloy [12] and Udimet 720Li [13] at intermediate temperatures (500 and $400{ }^{\circ} \mathrm{C}$, respectively).

The observed behaviour at RT and $T>550^{\circ} \mathrm{C}$ is typical for materials exhibiting strain localization due to repeated cutting of shearable precipitates. After an initial period of cyclic hardening the formation of deformation bands leads to loss of strength and cyclic softening commences. This is well documented for $\gamma^{\prime}$ (and $\gamma^{\prime \prime}$ ) strengthened superalloys with fine particle size. Different mechanisms have been proposed to explain the softening, e.g. loss of ordering [14], reduced slip resistance due to precipitate shearing [15] or fragmentation [16]. A common feature of all proposed explanations is the idea of dislocations cutting the particles. The different mechanisms will most likely all be operative to varying degrees, alone or in parallel, depending on the alloy and deformation conditions considered.

The increased cyclic hardening at $400{ }^{\circ} \mathrm{C}$, on the other hand, is typical for materials exhibiting DSA, where the temporary immobilization of moving dislocations leads to an increased dislocation density. Figure $1 \mathrm{~b}$ shows the stress response in cycle 1,20 and at $N_{f} / 2$ as a function of temperature, where it can be seen that there is no effect on the yield stress (measured as $0.2 \%$ proof stress during the first cycle). The maximum stresses at cycle 20 (roughly corresponding to the peak stresses at RT and $T \geq 550^{\circ} \mathrm{C}$ )
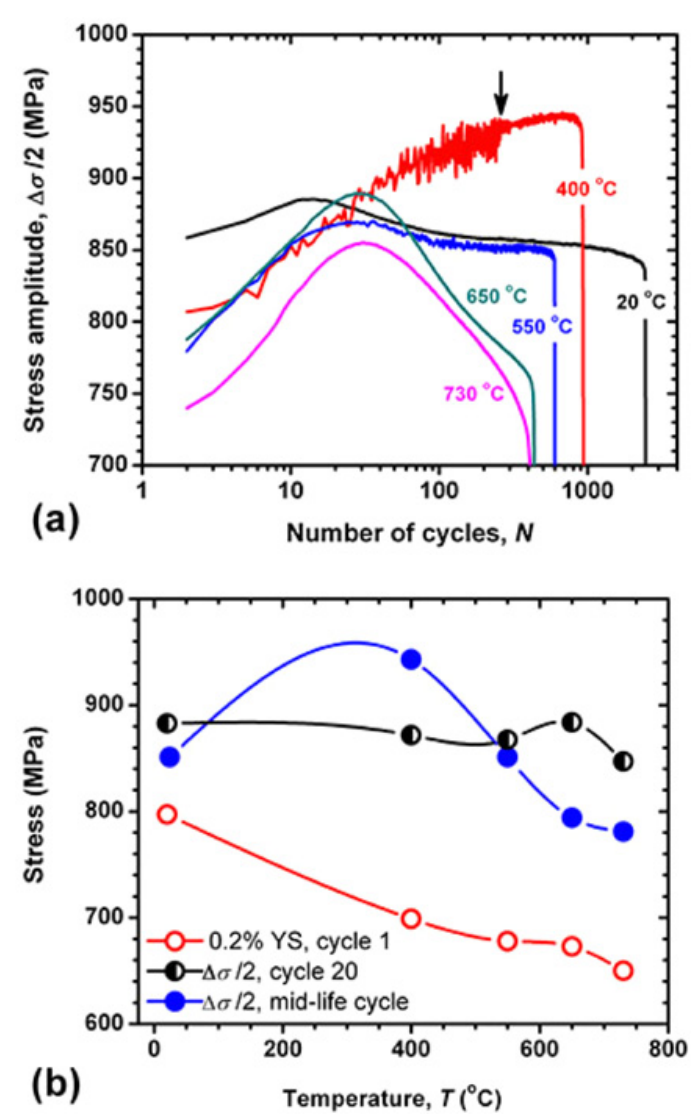

Figure 1. (a) Stress amplitude development vs. cycle number. (b) Stress levels at selected cycles vs. temperature.

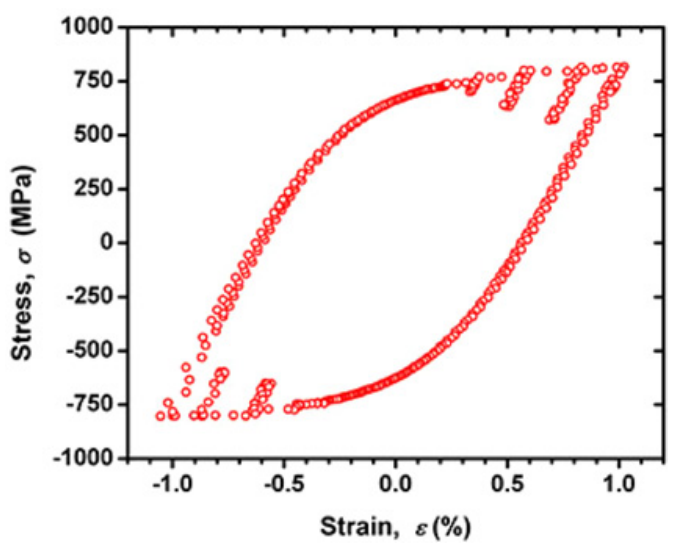

Figure 2. Hysteresis loop from test at $400^{\circ} \mathrm{C}$ (third cycle), showing serrated yielding in both tension and compression.

are relatively similar for all temperatures. No obviously anomalous temperature effect is seen here either, but the subsequent continuous cyclic hardening at $400^{\circ} \mathrm{C}$ is in stark contrast to the other temperatures.

In addition, there is a larger "noise" in the data obtained at 400 and $550^{\circ} \mathrm{C}$. This is especially pronounced in the first part of the fatigue life at $400^{\circ} \mathrm{C}$ (up to the point indicated by an arrow in Fig. 1), but persists throughout the fatigue life for both temperatures. This is connected to the occurrence of serrated yielding, which is a typical feature of DSA. Figure 2 shows cycle number 3 from the test at $400^{\circ} \mathrm{C}$, where serrations can be clearly seen. 


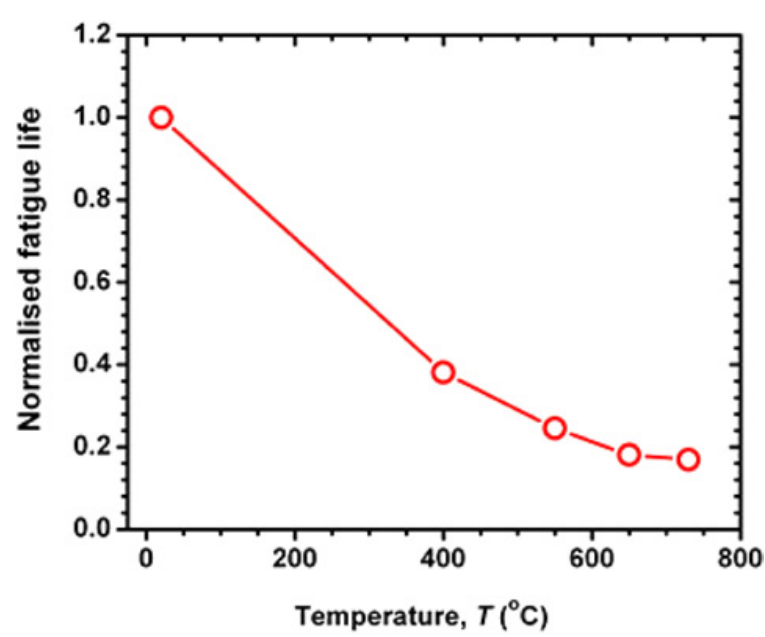

Figure 3. Temperature dependence of the fatigue life (normalised by room temperature value).

The dominating serration type appears to be $\mathrm{C}$ (significant stress drop below the general level, see Ref. [10] for a definition of serration types), but there is a pronounced type D component superimposed where the stress level after a drop is distinctly higher than before the drop. The serrations gradually disappear, while progressively changing character to more type D serrations, and cannot be seen after around $N=270$. As mentioned, the noise persists in spite of the disappearance of the serrations, but the magnitude is reduced. At $550{ }^{\circ} \mathrm{C}$, first type $\mathrm{C} / \mathrm{D}$ serrations are present up to about $N=10$. After this, no serrations are visible in the hysteresis loops until $N=50$ 60 , where they appear again as weak type D serrations (although the sampling frequency was not sufficient to reveal the nature of the serrations on a finer scale). Upon their return, the weak serrations are present until failure.

Comparing the fatigue lives at different temperatures does not reveal an influence of DSA. There is a continuous decrease in $N_{f}$ with increasing temperature, but there is nothing noteworthy at $400^{\circ} \mathrm{C}$ in this respect. However, to draw definite conclusions more testing at temperatures between RT and $400^{\circ} \mathrm{C}$, and preferably at other strain rates, should be performed.

\subsection{Tensile tests}

The results from the tensile tests are shown in Fig. 4a, and the full tensile curves (shifted vertically for clarity) are shown in Fig. 4b. There is no obvious effect of DSA on the yield or ultimate tensile stress levels, whereas a dip in the elongation and reduction of area, which is a typical feature connected to DSA, can be noticed at $400^{\circ} \mathrm{C}$.

From the Fig. $4 \mathrm{~b}$ the influence of DSA is clearly seen in the type $\mathrm{C}$ serrations observed at both 400 and $550^{\circ} \mathrm{C}$. At $550^{\circ} \mathrm{C}$ the serrations appear only at the higher strain rate, which is consistent with the established theories of thermal activation where the DSA region in $T-\dot{\varepsilon}$ space is shifted to higher strain rates with increasing temperature. As clear serrations are seen even in the LCF curves $\left(0.02 \mathrm{~s}^{-1}\right)$ at $400^{\circ} \mathrm{C}$, it can be concluded that the DSA region at this temperature is quite wide, spanning the entire range of tested strain rates $\left(1 \times 10^{-4}\right.$ to $\left.0.02 \mathrm{~s}^{-1}\right)$. At

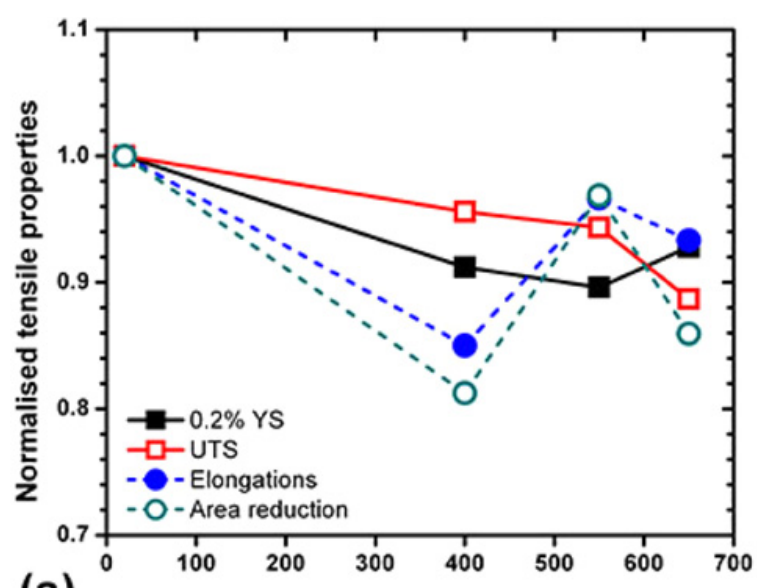

(a) Temperature, $T\left({ }^{\circ} \mathrm{C}\right)$

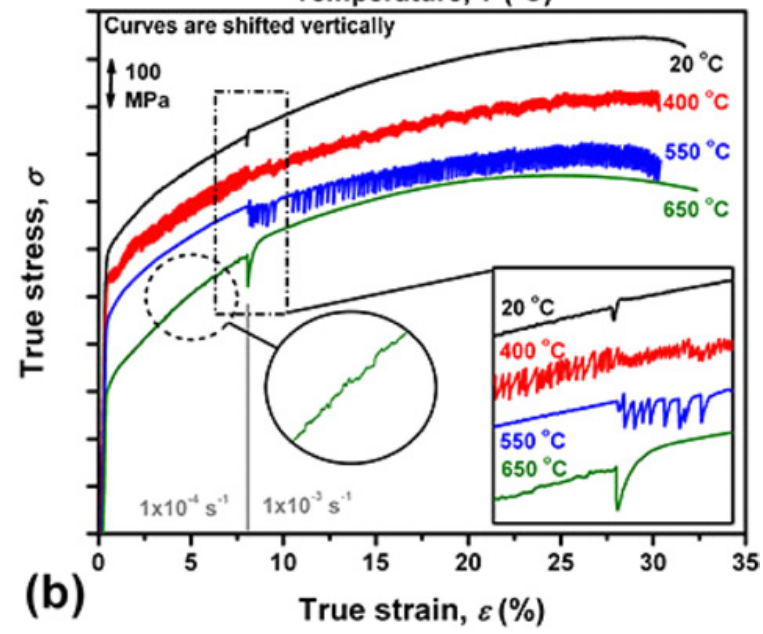

Figure 4. (a) Temperature dependence of the yield and ultimate tensile strength, elongation and area reduction (normalised by room temperature values). (b) Tensile curves (shifted vertically for clarity) at different temperatures. The rectangular box inserts show the stress response when changing the strain rate.

$550^{\circ} \mathrm{C}$ the lowest strain rate is below the region of active DSA and the strain rates during the LCF tests are close to the upper limit, judging from the weak but still observable DSA effects.

Furthermore, it can be noted that the strain levels actually decrease upon an increase in strain rate at 400 and $550^{\circ} \mathrm{C}$. This is characterised by the strain rate sensitivity, $m$, defined as

$$
m=\log \left(\sigma_{2} / \sigma_{1}\right) /\left.\log \left(\dot{\varepsilon}_{2} / \dot{\varepsilon}_{1}\right)\right|_{\varepsilon, T} .
$$

A negative strain rate sensitivity (decreasing stress with increasing strain rate) is a typical feature of DSA, where a lower strain rate allows longer time for diffusion and hence a more effective solute locking of the dislocations. The strain rate sensitivity evaluated from the strain rate jump in the tensile tests is shown in Fig. 5. The figure also includes value of $m$ calculated from the comparison of the $0.2 \%$ yield stresses obtained from tensile tests and the first LCF loop. Whereas the strain rate sensitivity from the tensile tests agrees with the previous observations of active DSA (negative $m$ ) in the intermediate temperature range, the values obtained from the comparison of 


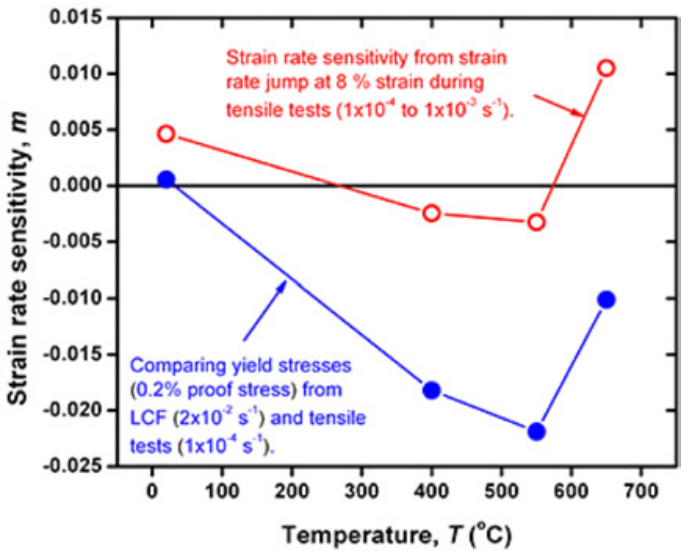

Figure 5. Temperature dependence of the strain rate sensitivity evaluated from both strain rate jumps in tensile tests and comparison of the $0.2 \%$ yield stress from tensile and LCF tests.

yield strengths are actually negative at all temperatures above RT.

One possible reason could be that there is another DSA region at higher temperatures, related to the diffusion of substitutional elements, whereas the intermediate temperature DSA is produced by interstitial elements such as carbon. Such double regions have been observed e.g. in [7]. The subsitutional-related DSA should occur at higher temperatures and lower strain rates, since the diffusivity is considerably lower compared to that of interstitial elements. Thus, the stresses would be higher at the lowest strain rate at $650^{\circ} \mathrm{C}$, while no effects of DSA are observable at $0.02 \mathrm{~s}^{-1}$ during the LCF tests. Looking closely at the stress-strain curves at $650^{\circ} \mathrm{C}$ (see insert in Fig. 4b) it is clear that type A serrations indeed are present at $1 \times 10^{-4} \mathrm{~s}^{-1}$. Type A serrations are often connected to DSA caused by substitutional atoms, supporting the above hypothesis. After the strain rate jump the serrations can still be seen, but they are much weaker.

Based on the relationship between stress drop, temperature and strain rate proposed in [17] and considering that the magnitude of the stress drops is roughly independent of strain, the activation energy for DSA can be estimated from the data at $400^{\circ} \mathrm{C}$. The resulting value is $47.6 \mathrm{~kJ} / \mathrm{mol}$, which is indicative of carbon being the responsible species. Typical activation energies for DSA in superalloys at intermediate temperatures, where carbon is claimed to be responsible, are in the range $50-130 \mathrm{~kJ} / \mathrm{mol}$, see e.g. [4-9]. This is usually compared to the activation energy for diffusion of $\mathrm{C}$ in $\mathrm{Ni}(138 \mathrm{~kJ} / \mathrm{mol}$ for lattice diffusion and $69 \mathrm{~kJ} / \mathrm{mol}$ for pipe diffusion [18]). The connection is usually made based on the observation of the activation energy for serrated flow in Ni-C alloys, which was measured to $63 \mathrm{~kJ} / \mathrm{mol}$ [19]. However, serrated flow in $\mathrm{Ni}-\mathrm{C}$ occurred in the temperature range -25 to $225^{\circ} \mathrm{C}$, significantly lower than usually observed in superalloy (although serrated flow in Alloy 718 at room temperature has been reported [20]). A study of $\mathrm{C}$ tracer diffusion in $\mathrm{Ni}-\mathrm{Cr}-\mathrm{Fe}$ alloys resulted in activation energies for carbon diffusion on the range 150-200 kJ/mol [21], increasing with alloying content, which explains the higher temperature for DSA in commercial multi-component
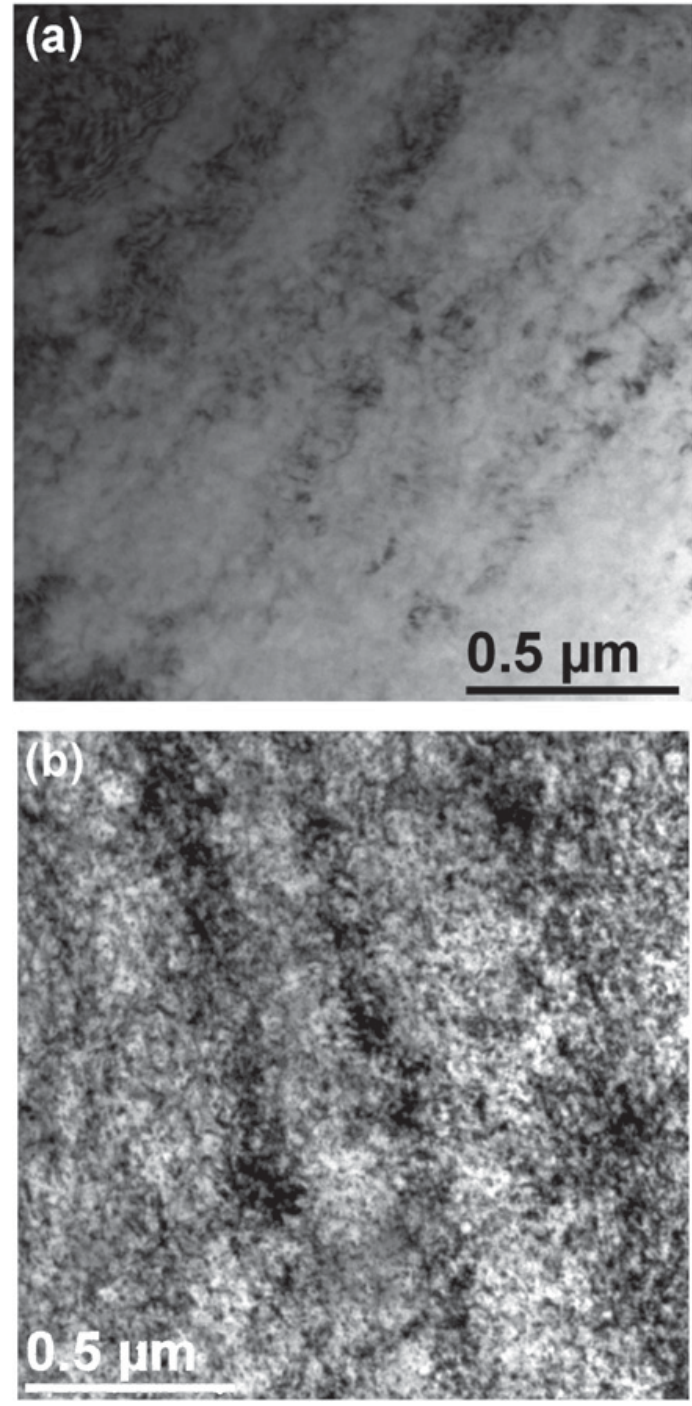

Figure 6. Bright field TEM images of the dislocation structures in fatigued specimens tested at (a) $400{ }^{\circ} \mathrm{C}$ and (b) $650^{\circ} \mathrm{C}$, showing localisation to deformation bands.

alloys. Given that pipe diffusion is expected to result in activation energies around half that of that for lattice diffusion [22], the measured values in [21] correspond to realistic estimates in the order of $75-100 \mathrm{~kJ} / \mathrm{mol}$ for $\mathrm{C}$ induced DSA.

Substitutional diffusion on the other hand (usually attributed to chromium) results in values around 180 $260 \mathrm{~kJ} / \mathrm{mol}$, see e.g. [6-9], to be compared with typical activation energies for diffusion of e.g. $\mathrm{Fe}$ and $\mathrm{Cr}$ in Ni$\mathrm{Fe}-\mathrm{Cr}(250-300 \mathrm{~kJ} / \mathrm{mol}$ for lattice diffusion and around $200 \mathrm{~kJ} / \mathrm{mol}$ for grain boundary diffusion) [23].

It should be noted that some authors claim that DSA could be explained by substitutional elements even at intermediate temperatures where the measured activation energy was around $90 \mathrm{~kJ} / \mathrm{mol}$ [24]. The argument is that the activation for substituional diffusion is the sum of the energy for vacancy formation and migration, and if only the migration energy is considered the values are in the order of $100 \mathrm{~kJ} / \mathrm{mol}$.

The present result is somewhat lower than the typically observed for carbon, but it is only a rough estimate 


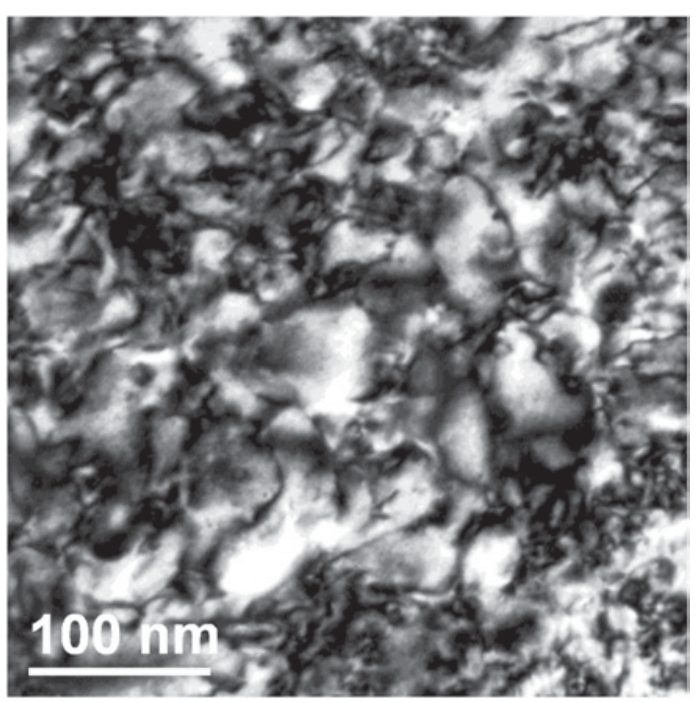

Figure 7. Bright field TEM image of the dislocation structure within a deformation band in a specimen fatigued at $400^{\circ} \mathrm{C}$, showing bowing dislocations and little evidence of shearing.

based on two points (rather than the conventional way of using linear regression to multiple data points) and primarily serve as an order-of-magnitude indicator. Also, when different methods to estimate the activation energy are compared, the stress drop method usually produces lower values $[6,7]$.

\subsection{Dislocation structures}

Figure 6 shows bright field TEM images of the dislocation structures in specimens fatigued at 400 and $650^{\circ} \mathrm{C}$. At both temperatures there are clearly visible deformation bands, with band widths in the range 100-200 $\mu \mathrm{m}$ and interband spacing of the same order. Tilting reveals a high density of homogeneously distributed dislocations in the regions between the bands. There is no clear difference between the two temperatures based on the present results, although the band width appear to be somewhat smaller at $400^{\circ} \mathrm{C}$. However, so far only limited work has been performed and future investigations will aim to quantitatively characterise the dislocation structures as a function of temperature. In spite of the banded structure, there are no indications of precipitate shearing within the bands. Dark field imaging of the precipitates using the $\gamma^{\prime}$ superlattice reflection shows no obviously sheared particles, and the bright field image (Fig. 7) clearly shows bowing of dislocations between precipitates.

The observed deformation substructures agree well with previous high-temperature LCF studies of e.g. Waspaloy [12,25] and Udimet 720Li [13] with $\gamma^{\prime}$ precipitates larger than around $25 \mathrm{~nm}$. Coarse deformation bands were reported, with a high density of dislocations forming homogenous networks between the bands. Deformation in the bands occurred by looping [25] or combinations of shearing and looping $[12,13]$. The dislocation density in Waspaloy had its maximum at $500^{\circ} \mathrm{C}$, consistent with the idea of active DSA.

Valsan at al. [26] showed that Nimonic PE-16 aged Nimonic PE-16 tested under LCF conditions at temperatures above $450{ }^{\circ} \mathrm{C}$ and strain rates below $3 \times 10^{-4} \mathrm{~s}^{-1}$ exhibited numerous signs of DSA, such as serrated yielding, reduced fatigue life, increased cyclic hardening, negative strain rate sensitivity. The investigation did not include studies of the deformation substructures, but observations of the outer surface confirmed that there was an increased deformation band spacing with decreasing strain rate, which is indicative of increased strain localisation.

\section{Conclusions}

The present investigation concernes the effect of dynamic strain aging (DSA) on the mechanical behaviour of Nibase superalloy Haynes 282 during both monotonic and cyclic deformation. The results show that:

1. DSA is an active phenomenon during both deformation types at intermediate temperatures $\left(400-550^{\circ} \mathrm{C}\right)$. The probable species responsible is carbon, based on approximate estimates of the activation energies. In this temperature range serrated yielding and negative strain rate sensitivity can be observed. During cyclic deformation there is a pronounced cyclic hardening at $400{ }^{\circ} \mathrm{C}$, where also the serrations are most pronounced. There is a small effect on the tensile ductility, but no apparent reduction in the fatigue life.

2. At higher temperatures DSA can be active at the lowest strain rates $\left(1 \times 10^{-4} \mathrm{~s}^{-1}\right)$, and is then presumably caused by substitutional alloying elements, rather than carbon.

3. TEM studies of the dislocation structures indicate that there is a significant degree if strain inhomogeneity during cyclic deformation at intermediate and high temperatures. In spite the occurrence of deformation bands and observations of cyclic softening, precipitate looping was the dominating deformation mode. Further TEM studies are necessary to quantify the effects of DSA on the deformation substructure.

\section{References}

[1] L.M. Pike, Proceedings of Superalloys 2008, TMS, 191 (2008)

[2] L.M. Pike, Proceedings of ASME Turbo Expo 2006, ASME, GT2006-91204 (2006)

[3] P.G. McCormick, Acta Metall. 20, 351 (1972)

[4] R.W. Hayes, W. C. Hayes, Acta Metall. 30, 1295 (1982)

[5] K. Gopinath, A.K. Gogia, S.V. Kamat, U. Ramamurty, Acta Mater. 57, 1243 (2009)

[6] C.L. Hale, W.S. Rollings, M.L. Weaver, Mat. Sci. Eng. A 300, 153 (2001)

[7] A. Nagesha, S. Goyal, M. Nandagopal, P. Parameswaran, R. Sandhya, M.D. Mathew, S.K. Mannan, Mat. Sci. Eng. A 546, 34 (2012)

[8] S.A. Nalawade, M. Sundararaman, R. Kishore, J.G. Shah, Scripta Mater. 59, 991 (2008)

[9] W. Chen, M.C. Chaturvedi, Mat. Sci. Eng. A 229, 163 (1997) 
[10] P. Rodriguez, Bull. Mater. Sci. 6, 653 (1984)

[11] S.L. Mannan, Bull. Mater. Sci. 6, 561, (1993)

[12] B.A. Lerch, N. Jayaraman, S.D. Antolovich, Mat. Sci. Eng. 66, 151 (1984)

[13] K. Gopinath, A.K. Gogia, S.V. Kamat, R. Balamuralikrishnan, U. Ramamurty, Acta Mater. 57, 3450 (2009)

[14] R.E. Stoltz, A.G. Pineau, Mat. Sci. Eng. 34, 275 (1978)

[15] B. Lerch, V. Gerold, Acta Metall. 33, 1709 (1985)

[16] M. Sundararaman, W. Chen, V. Singh, R.P. Wahi, Acta Metall. Mater. 38, 1813 (1990)

[17] E. Pink, A. Grinberg, Acta Metall. 30, 2135 (1982)

[18] Gale WF, Totemeier TC, editors. Smithells metals reference book. London: Butterworth-Heinemann; 2004. p. 3-25
[19] Y. Nakada, A. S. Keh, Acta Metall. 18, 437 (1970)

[20] K. Bhanu Sankara Rao, S. Kalluri, G.R. Halford, M.A. McGaw, Scripta Metall. Mater. 32, 493 (1995)

[21] J. Cermák, H. Mehrer, Acta Metall. Mater. 42, 1345 (1994)

[22] R.W. Balluffi, phys. stat. sol. 42, 11 (1970)

[23] J. Cermák, Mat. Sci. Eng. A 148, 279 (1991)

[24] V. Shankar, M. Valsan, K. Bhanu Sankara Rao, S.L. Mannan, Metall. Mater. Trans. A 35A, 3129 (2004)

[25] M. Clavel, A. Pineau, Mat. Sci. Eng. 55, 157 (1982)

[26] M. Valsan, D.H. Sastry, K. Bhanu Sankara Rao, S.L. Mannan, Metall. Mater. Trans. A 25A, 159 (1994) 